\title{
Medical Education Amid the COVID-19 Pandemic
}

\author{
Puneet Kaur Sahi ${ }^{1}$, Devendra Mishra ${ }^{1,2}$ and Tejinder Singh ${ }^{3}$ \\ From Departments of ${ }^{1}$ Pediatrics and ${ }^{2}$ Medical Education, Maulana Azad Medical College, New Delhi; and ${ }^{3}$ Departments of \\ Pediatrics and Medical Education, SGRD Institute of Medical Sciences and Research, Amritsar, Punjab; India. \\ Correspondence to: Dr Puneet Kaur Sahi, Department of Pediatrics, Maulana Azad Medical College and Lok Nayak Hospital, New \\ Delhi110002,India.puneetksahi@gmail.com
}

\begin{abstract}
The coronavirus pandemic has shaken the mankind to its core. Social distancing is the most important preventive strategy for the spread of this contagion, short of a vaccine. Implementation of the same has forced many countries in to a complete lock-down. Closure of schools and universities has made education uncertain at all levels. Medical education is no exception. In this pandemic, the need for uninterrupted generation of future doctors is felt more than ever in our living memory. Continuity of medical education is thus imperative. While "Live" patient contact is an irreplaceable tenet of clinical teaching, these extraordinary times demand exceptional measures. Pedagogical innovations involving technology and simulation based teaching (Online lectures, video case vignettes, virtual simulators, webcasting, online chat-rooms) need to be brought to the forefront. Since the medical educators have been pushed inevitably to rely on technology-based learning, they should not only embrace it but also develop and evaluate its sustainability and application in preclinical and clinical setting. Meanwhile, the students, whose medical education is stuck in this pandemic time, should realize that there is no better teacher than a first-hand experience, and they are eyewitnesses to the making of history.
\end{abstract}

Keywords: Coronavirus, e-Learning, Medical student, Pedagogy.

Published online: May 14, 2020; PII: S097475591600181

T he SARS CoV-2, a mutated sub-microscopic agent lacking a true existence of its own, has brought the world to a standstill (literally and metaphorically). Several countries have gone in to a complete lock-down to limit the spread of the Coronavirus disease 2019 (COVID-19) pandemic. The primary focus has rightly been on curbing the disease spread in the community, rapid development and reorganization of available medical resources to cater to the increasing patient load and adequate care of the infected ones. Most other things have taken a backseat. Education at all levels has become uncertain due to the mass closures of schools and universities. Medical education, particularly, at the medical school/undergraduate level, has been no exception.

\section{HOW HAS MEDICAL EDUCATION BEEN AFFECTED?}

The premise for closing medical universities is dual medical students' safety may be jeopardized during clinical rotations putting them at risk of exposure to COVID-19 positive patients, and/or infected students may themselves become the portal of spread of the disease [1]. Even for preclinical medical students, social distancing measures have precluded the conduct of classroom-based teaching and discussions [2]. In the wake of this global emergency, medical education has been existentially challenged.
In certain countries like the US, the pandemic has coincided with the time of educational transition [3]. A steep rise in the infection rates has forced a complete removal of the students from the clinical rotations [4] and halting of all summative examinations. Several Canadian, UK and Australian schools have taken similar urgent steps [5,6]. As a result, scores of medical students have been affected with final year medical students stuck just short of graduation. In countries like India, where the educational transition has already occurred, the current clinical rotations have been halted. A particular concern is the implementation of the new competency-based curriculum for the students admitted in 2019. Almost all the institutions in the country had put up a day-by-day time table covering the entire phase 1 , which is going to be disrupted. Additionally, it was about the time to prepare for the phase 2 in terms of objectives, integration and preparing schedules. Teachers of phase 2 also needed training for the new curriculum. This process has been paused. Medical students (admitted both pre-2019 and post-2019) will suffer a reduced exposure to certain clinical branches or a proportionally shortened rotation in all clinical branches. In the worst-case scenario, where the pandemic continues for an unforeseeable time, an extension of the medical training period may be warranted. In all situations, the medical students will be at a loss. 
Thus, the medical educators need to rapidly evolve the methods of teaching to minimize the onslaught of disrupted medical education, while also building innovative systems to accommodate the medical student cohorts stuck in the time of this pandemic. Medical Council of India has come out with its guidance for medical students in the current situation [7].

\section{WHY SHOULD MEDICAL EDUCATION CONTINUE?}

There are three important reasons for ensuring continuation of medical education in this hour. Firstly, learning the science and art of medicine is a graduated process, it is imperative that a student completes one milestone before embarking on the next. A student who misses any part of the education is likely to find it difficult to join the dots later. Secondly, if clinical rotations are deferred for the current student cohort and clubbed with others, the density of learners would impair the clinical learning experience (especially in geographic areas like India where the learner density is already very high). Lastly, recognizing the possibility that the current pandemic may take a reasonable time to abate, there may arise a paucity of healthcare workers. In such situations, students may need to engage in certain aspects of patient care while the authorities ensure their safety, learning and if applicable, remuneration.

Therefore, it is essential that we adopt new ways that facilitate the ongoing knowledge and skill development of the next generation of health professionals.

\section{MAINTAINING THE CONTINUITY OF MEDICAL EDUCATION}

To answer this, we may first reiterate that undergraduate medical education the world over is divided into an initial foundation of preclinical teaching (lasting 12-24 months) followed by the core of clinical rotations or clerkships (lasting 24 months) in medical schools following the conventional model [1]. This is followed by internship where the student works with the treating team as a supervised learner. Finally, as per the concerned university's regulations, the medical student applies for/ appears for entrance exams to specialized courses (residency or post-graduation) during the final year of medical school or during internship.

Conventionally, the preclinical teachings have involved lectures, small group discussions and laboratory sessions. For the past decade, the medical fraternity has been trying to improvise pedagogy by introducing technology-based novel concepts such as flipped lectures and simulation-based learning [8,9]. Though, many medical schools have become well versed with these concepts, in several countries including India, technology-enhanced learning is still in its infancy. In wake of the COVID-19 pandemic, a number of medical schools have rapidly converted their entire pre-clinical curriculum to online formats involving online lectures, webcasting and virtual group discussions. However, such transition may be slower in places where technology enhanced learning is still developing and online lectures still need to be prepared, especially when a large part of the medical fraternity has been redirected to fight the COVID-19 pandemic. While enforcement of technologybased learning has become a necessity in this hour, we need to ponder upon the advantages and barriers it may pose. Online formats allow the students an easy accessibility to educational material as per their convenience, in their preferred environments and repeatedly. Pitfalls include isolation due to shifting from the medical school setting to home, reduced discussions with peers, increased dependence on email and an uninterrupted internet access, and a struggle to delineate boundaries between work and home [1]. There have been instances of many medical schools in India having started online lectures for students; however, most of these are conventional lectures delivered through electronic mode, without paying much attention to the pedagogical requirements of online learning. Additionally, very few have incorporated the assessment component in these.

Clinical teachings, on the other hand are best learnt bedside with a 'live' patient. Not only does the medical student get a first-hand experience of patient's clinical findings but also learns about the dynamics of patient interaction, psychology and counselling. In addition, development of a student's professional identity is often shaped by medical teachers who they see as role models and who can infuse the cultures of altruism. However, in the times of this contagious pandemic, an alternate model is needed wherein some form of clinical education continues despite curtailment of real patient contact. Cues can be taken from the past. During the SARS outbreak which preferentially affected the healthcare workers [10], an infection of 17 medical students provoked rapid closure of the Chinese university in Honk Kong in 2003 [11]. This period saw heavy reliance on technology-based learning to provide some continuum to clinical teaching. These included webcasting, videotaped vignettes, audio-recordings, problem-based learning tutorials on online chat rooms and mannequin simulators $[11,12]$. Over the years, technology has matured. The current situation demands use and furthering of these pedagogical innovations. Use of e-learning modules (flash multimedia and digitized images), patient surrogates such as virtual patients (to teach clinical 
examination, procedural, diagnostic skills and communication skills) and virtual-reality simulators (to teach palpation, surgical and resuscitation skills) is needed. Simulators have shown to be as effective as live actor-patients for teaching purposes [13]. Despite the undoubted advantage of IT and simulation-based education, in the current situation, there are distinct disadvantages. The foremost is the fact that all these tools can be supplemental to clinical teaching but not a replacement. Secondly, setting up of a virtual learning environment or a simulation laboratory is costly and time taking, making it especially unsuited for the low and middle income countries. Thirdly, while virtual simulators will maintain the tenet of both non-contact with patient and social distancing amongst students, mannequin simulators will flout social distancing needs amongst students precluding their use currently.

Other important barriers that have prevented medical educators to dissipate e-teaching (during these emergent times and otherwise) include time constraints, poor technical skills, inadequate infrastructure and absence of institutional strategies. Proposed solutions include improved educator skills (which may not be feasible in the short-term, therefore tagging with people who already have these skills may help), inculcation of a positive attitude, and incentives/ reward for the time devoted to the development and delivery of online content [14].

While it may appear impressive to talk about online/ digital/simulation-based learning, the fact remains that in India, we are still far away from such modalities [15]. It requires planning, trained manpower and finances to embark upon such methods. In such times, it may be very useful to have a central agency (like MCI) to take the lead and develop pedagogically useful learning content. A mandatory component of formative assessment also needs to be included to ensure attainment of learning objectives. Having a common curriculum and rotation schedule for all colleges of India could prove to be a blessing in disguise, allowing us to have centrally prepared material. Many colleges in the public sector and some in private sector have good equipment which can be put to use. Availability of scattered expertise across institutions can be collated for better results. There have been some recent publications from India to highlight the role of social media as a tool for engaging students $[16,17]$. Similarly, existing professional networks can be used for webinars on important topics.

Last year, the MCI had embarked on a digital project to monitor teaching in colleges using closed-circuit television (CCTV) cameras and currently most colleges have such systems in place [18]. This infrastructure can be put to reverse use by streaming content from MCI to all colleges, which can subsequently be accessed by students by logging on to their institutional servers.

In addition to the use of above tools, there may be a few measures that may smartly squeeze some moments of clinical learning for the medical students. These include modification of the academic roster (preponing scholarly work and deferring clinical rotations to a later time frame) which may be feasible at certain medical centers as per their learning goals. Also, students may be involved in the tele-health consultations (which have become far commoner during this pandemic). Most importantly, they may serve as educators to their peers, patients and communities by developing educational materials and videos, thus influencing behaviors in a positive way to prevent the spread of the pandemic. Students may update themselves with authentic online resource related to the COVID-19 pandemic; learn via following the pandemic trajectory worldwide and understanding how the situations are being dealt. With updated knowledge, they may engage in projects involving development of videos (eg, videos demonstrating donning and doffing of PPE, proper mask fitting and hand washing techniques) or help in preparing indigenous PPE, in the process educating themselves. No number of lectures can match the impact of things learnt via first-hand experience of the SARSCov-2 pandemic.

As far as the postgraduate students are concerned, they have been deployed as a part of COVID workforce, their work areas defined as per their specialization subject and year of ongoing post-graduation. An infodemic of COVID-19 has flooded the social and news media. It is the medical educators' role to provide the residents with the most reliable and latest information from the official government and hospital websites. Repeated training regarding PPE, donning and doffing, COVID-19 sampling, patient handling, transport and treatment is being conducted via online reading material, videos, webinars and cloud computing platforms (Like Zoom, G Suite, Office 365). While the resident teams on duty are engaged in active learning of COVID-19, those who are in quarantine/ reserve teams may participate in self-directed online group discussions on other important topics of their specialty. Medical educators may guide in identification of these topics and moderate such discussions. Case vignettes may be presented and discussed. Many e-learning activities are already being conducted, albeit a formative assessment component needs to be integrated into the framework.

Thus, the options are continually evolving. Box I shows the various available tools while Box II enlists the 


\section{Box I Available Tools and Platforms to Continue Medical Education Amid the COVID-19 Pandemic}

\section{Available Tools}

- Online videos, power point presentations, handouts, flash multimedia and digitised images developed by individual medical universities.

- Smartphones with user-friendly apps e.g., dosage calculators, growth charts, Curofy, Docplexus, SCAT, webbased features e.g., PubMed for handheld devices, social media apps e.g., Facebook, WhatsApp, and YouTube.

- Webcast (i.e. broadcast of recorded presentation over the internet) e.g., Webcasts made by professional bodies like the Indian Academy of Pediatrics.

- Webinars i.e. broadcast of live presentation over internet allowing an interactive session e.g., webinars organized by IAP at the dIAP platform.

- Video conferencing (case discussion/panel discussion on computer platforms).

- Virtual simulation technology.

Available Platforms*

- Cloud - computing platforms like Zoom, G-Suite which allow video conferencing.

- TUSK platform contains full-text syllabi, slides, lecture recordings (audio and video), class schedules, course evaluations, dissection guides, a quiz and case maker, grade book, and other resources made available by the faculty, e.g., Christian Medical College, Vellore has utilized it to educate their undergraduates while they work in rural areas.

- Online Google groups Ex: Listserv is being used as an e-learning platform in the FAIMER fellowship conducted at various centers in India.

- Telemedicine software system developed by the Centre for Development of Advanced Computing connects many medical institutes of India.

- EDUSTAT is the first Indian satellite meant exclusively for distance education e.g., lectures are being delivered for medical undergraduates in Punjab.

Prepared from ref. 15 and 16. *These are a few most prominent examples and not an all-encompassing list.

various possible strategies that may be used for continuing medical education in these times in the Indian set-up. The most reasonable strategy will be for every medical school to model continued pre-clinical and clinical teachings to match with the available resources.

\section{METHODS OF ASSESSMENT AND LICENSURE}

In medical universities, where students were in the phase of transition to the next years, examinations have been delayed. For example, in the US, the second and third year undergraduate summative examinations have been put on hold and the organization that operates these testing centers has temporarily closed its facilities [3]. Such delays are demotivating for the exam-going students and may put their career path on the back foot, if the closures extend. In universities where the final year medical students have been selected for a residency, early graduation should be considered a viable option. The medical education systems are already emphasizing the need for achievement of core competencies rather than mere completion of a stipulated time period in a subject.
Therefore, in these pressing times, it may be suitable to give leeway to medical universities to decide which medical students have completed the necessary competencies for graduating to the next level, as already done in the US [5]. This will not only provide a boost to the students but also add to the healthcare work-force, who can step up per the demands of the situation. In India, the same situation of transition applies to the final year residents who are at the cusp of their post-graduation. The MCI has directed them to continue working in their respective universities to add to the anti-COVID workforce. An early post-graduation for these residents based on sturdy assessment merits a thought. An internal committee may be formed by MCI to decide criteria for eligibility for such an expedited degree.

Nevertheless, an important point to contemplate is the method of summative assessment to be employed while maintaining social distancing. In the past, during the SARS outbreak in 2003, the summative examinations at certain universities were conducted via telephone conference-based viva voice [11]. Though, it is subject to 
Box II Possible Strategies to Continue Medical Education for Different Groups Amid the COVID-19 Pandemic

Medical undergraduate (UG) students.

- Attend online teaching per faculty prepared roster.

- Engage in self-assessment and peer assessment to ensure attainment of desired learning objectives.

- Discuss with faculty for moderating the setting of desired learning objectives.

- Serve as educators to their peers, patients and communities by developing educational materials and videos regarding COVID-19.

- Engage in supervised telehealth consultations

- Engage in projects involving development of indigenous PPE.

Medical postgraduate (PG) students

- The PGs may be involved in care of COVID-19 patients/samples/imaging as per their specialty; quarantined/reserve PG teams should engage in online teaching concerned to their specialty and use all strategies as suggested for UGs.

Medical educators/faculty

- Prepare resource material for online power point presentations, videos, webinars, webcasts.
- Prepare formats for online case discussions.

- Prepare a roster/schedule for various pre-clinical and clinical online teaching.

- Device methods of formative assessment integrated with above.

- Continue medical education training using.

University administrators

- Invest in improving educator skills in imparting online teaching.

- Invest in developing an online pedagogical repository.

- Provide incentives/ reward to involved faculty for the time devoted to the development and delivery of online content.

- Inculcate a positive attitude in all involved in e learning/teaching.

- Collaborate public and private sector resources (both technology and education material) to allow rapid chalk out of e-content with wide dispersal.

- Engage $\mathrm{MCl}$ in supervising and guiding all universities in delivery of online-teaching.

- Take feedback from universities for continuous improvement of e-teaching methods. availability of an uninterrupted internet access, it may be feasible in dire situations. Supplemental methods may involve online web-based clinical case viva, demonstration of practical skills on virtual mannequins and use of digitized images for spotters. In a routine situation, these methods of assessment would sound very odd, but we are living in extraordinary times demanding extraordinary measures. In India, most undergraduates are in the second quarter of their respective academic years and have a long way to go before appearing for their summative examinations. However, whether the ongoing technology-based teaching efforts/ self-learning efforts are leading to fulfillment of desired learning objectives is a definite concern. Formative assessments should therefore be integral to such efforts. Using either existing quizzes apps or indigenously developed ones can be shared amongst institutions for this purpose. Gamification is another upcoming modality; though, it will need time to be cultivated. Meanwhile, selfassessment and peer assessment are methods which may be suited to current situation and may be encouraged while educators moderate this process.

\section{PLAN FOR THE FUTURE}

A solid take away from the situation that we face today is that we need to prepare for continuing medical education, not only for now but also for possible future contagions. An excellent approach to continuing teaching and training in medical education field was published a decade back based on whether only patient-student contact is to be curtailed or all forms of contact (patientstudent, student-student, teacher-student) need to be disrupted [19]. The ongoing pandemic has already put resource development for continuing education on a fast track. However, it will be reasonable to invest in these pedagogical innovations over the long-term and develop a repository of the requisite sources beforehand.It may also be the right time to prepare a plan B for future exigencies by involving regulators, universities, educational experts and professional associations.

\section{CONCLUSIONS}

How do we choose to see the glass: half full or half empty? Our optimist's mind tells us that this period of 'no teaching' can be the period of 'greatest learning'. Medical students are watching first-hand the principles of epidemiology in practice and are more aware of the dynamics of a pandemic, use of PPE, and importance of hand hygiene. Additionally, many students have the time now to catch up on their previous studies. Medical 
educators have been provided with the perfect opportunity to develop and evaluate the suitability and application of technology-based learning. Medical regulatory bodies and associations have the most important reason to connect and integrate education materials and methodologies. And humanity has rediscovered the value of enjoying the little things in life!

Pedagogically speaking, this time is likely to bring out medical ingenuity. Whether online teaching becomes a standard mode of pre-clinical education, and virtual and simulation technology an integral part of clinical education is for time to see, but the seeds for a paradigm shift already seem to be have been sown.

Contributors: PKS: Reviewed literature, drafted the manuscript; DM: concept, manuscript plan, and inputs in manuscript preparation; TS: contributed to manuscript planning, and provided critical inputs in preparation and finalization.

Funding: None; Competing interest: None stated.

\section{REFERENCES}

1. Rose S. Medical student education in the time of COVID19. JAMA. March 31, 2020. Available https://www.ncbi. nlm.nih.gov/pubmed/32232420. Accessed April 1, 2020.

2. Del Rio C, Malani PN. 2019 Novel coronavirus Important information for clinicians. JAMA. February 5, 2020. Available from: https://www.ncbi.nlm.nih.gov/ pubmed/32022836. Accessed April 1, 2020.

3. Murphy B. Four questions medical students are asking on the COVID-19 pandemic. Public Hlth. 2020 March 24. Available from: https://www.ama-assn.org/deliveringcare/public-health/4-questions-medical-students-areasking-covid-19-pandemic. Accessed April 1, 2020.

4. Association of American Medical Colleges. Important guidance for medical students on clinical rotations during the coronavirus (COVID-19) outbreak. Press release. (Published March 17, 2020). Available from: https:// www.aamc.org/news-insights/press-releases/important guidance-medical-students-clinical-rotationsduringcoronavirus-covid-19-outbreak. Accessed April 1, 2020.

5. Liaison Committee on Medical Education. COVID-19 updates and resources. (Updated March 25, 2020). Available from: https://lcme.org/covid-19/. Accessed April 1, 2020.

6. Medical Schools Council. Information for medical students. Updated March 13, 2020. Available from:https:// www.gmc-uk.org/news/news-archive/coronavirusinformation-and-advice/information-for-medical- students. Accessed April 8, 2020.

7. Medical Council of India. Advisory regarding UG classes in view of COVID-19 epidemic. Medical Council of India. Published March 23, 2020. Available from: https:// mciindia.org/MCIRest/open/getDocument? path $=/$ Documents/Public/Portal/LatestNews/Advisory-COVID19-all\%20colleges.pdf. Accessed on April 8, 2020.

8. Irby DM, Cooke M, O'Brien BC. Calls for reform of medical education by the Carnegie foundation for the advancement of teaching: 1910 and 2010. Acad Med. 2010;85:220-7.

9. Skochelak SE, Stack SJ. Creating the medical schools of the future. Acad Med. 2017;92:16-9.

10. Maunder RG, Lancee WJ, Balderson KE, Bennett JP, Borgundvaag B, Evans S, et al. Long-term psychological and occupational effects of providing hospital healthcare during SARS outbreak. Emerg Infect Dis. 2006;12: 1924-32.

11. Patil NG, Chan Y, Yan H. SARS and its effect on medical education in Hong Kong. Med Educ. 2003;37:1127-8.

12. Abrahamson SD, Canzian S, Brunet F. Using simulation for training and to change protocol during the outbreak of severe acute respiratory syndrome. Crit Care. 2006;10:R3.

13. Gillett B, Peckler B, Sinert R, Onkst C, Nabors S, Issley S, et al. Simulation in a disaster drill: Comparison of highfidelity simulators versus trained actors. Acad Emerg Med. 2008;15:1144-51.

14. O'Doherty D, Dromey M, Lougheed J, Hannigan A, Last J, McGrath D. Barriers and solutions to online learning in medical education - An integrative review. BMC Med Educ. 2018;18:130.

15. Dhir SK, Verma D, Batta M, Mishra D. E-learning in medical education in India. Indian Pediatr. 2017;54:871-7.

16. Kapoor A, Tiwari V, Kapoor A. Teaching undergraduates beyond the classroom: Use of WhatsApp. Indian Pediatr. 2019;56:967-9.

17. Raiman L, Antbring R, Mahmood A. WhatsApp messenger as a tool to supplement medical education for medical students on clinical attachment. BMC Med Educ. 2017; 17:7.

18. Medical Council of India. Implementation of IP based CCTV solutions at Medical Colleges (DMMP-II) - Reg. April 12, 2019. Available from: https://mciindia.org/ MCIRest/open/getDocument?path=/Documents/Public/ Portal/LatestNews/Letter-all-college-DMMP-II01.03.2019-min_compressed.pdf. Accessed April 8, 2020.

19. Lim E CH, Oh V MS, Koh DR, Seet R CS. the challenges of "continuing medical education" in a pandemic era. Ann Acad Med Singapore.2009;38:724-6. 